\title{
Genetic Variability of Cercospora coffeicola from Organic and Conventional Coffee Plantings, Characterized by Vegetative Compatibility
}

\author{
R. B. Martins, L. A. Maffia, and E. S. G. Mizubuti
}

Departamento de Fitopatologia, Universidade Federal de Viçosa, MG, Brazil.

Accepted for publication 25 June 2008.

\begin{abstract}
Martins, R. B., Maffia, L. A., and Mizubuti, E. S. G. 2008. Genetic variability of Cercospora coffeicola from organic and conventional coffee plantings, characterized by vegetative compatibility. Phytopathology 98:1205-1211.

Cercospora leaf spot is a destructive fungal disease that has become a threat to the coffee industry in Brazil. Nevertheless, little is known about populations of its causal agent, Cercospora coffeicola. We evaluated the potential of using nitrogen-nonutilizing (nit) mutants and vegetative compatibility groups (VCGs) to characterize the genetic variability of the $C$. coffeicola population associated with coffee plantings in Minas Gerais state (MG), Brazil. A total of 90 monosporic isolates were obtained from

samples collected according to a hierarchical sampling scheme: (i) state geographical regions (Sul, Mata, and Triângulo), and (ii) production systems (conventional and organic). Nit mutants were obtained and 28 VCGs were identified. The 10 largest VCGs included $72.31 \%$ of all isolates, whereas each of the remaining 18 VCGs included $1.54 \%$ of the isolates. Isolates of the largest VCGs were found in the three regions sampled. Based on the frequencies of VCGs at each sampled level, we estimated the Shannon diversity index, as well as its richness and evenness components. Genetic variability was high at all hierarchical levels, and a high number of VCGs was found in populations of C. coffeicola associated with both conventional and organic coffee plantings.
\end{abstract}

Brazil is the largest coffee (Coffea spp.) producing country in the world. About $30 \%$ of all coffee beans traded in 2006 were from Brazil. Coffee is mostly grown in the southeastern part of the country, and Minas Gerais (MG) is the leading state in coffee production. More than $50 \%$ of the 2.5 million tons of Brazilianprocessed coffee in 2006 was produced in MG.

Coffee production is threatened by many diseases, including Cercospora leaf spot caused by Cercospora coffeicola Berk. \& Cke., which can cause severe losses. The pathogen infects leaves, fruits, and occasionally stems. Leaf symptoms are characterized by round necrotic lesions, with a brown outer ring and a graywhite center area, giving an eye-like appearance. Fruit spots appear as sunburned, black, dry, elliptical scars on the skin that make it difficult to pulp the affected cherries and reduce coffee quality. The greatest problem associated with the disease is leaf fall. During severe epidemics, leaf fall can reduce yield up to $30 \%$ (35). Until recently, the disease was of secondary importance and usually associated with plants under nutritional or water stress. However, in the last two decades, professionals in the coffee business sector have noticed an increase in Cercospora leaf spot intensity in plantings countrywide.

Coffee production systems in Brazil have changed during recent decades. Planting of new cultivars, expansion of production to new areas with peculiar edaphoclimatic conditions, such as the Cerrado, adoption of new crop systems, such as organic farming, which do not utilize synthetic chemical compounds for pest and

Corresponding author: L. A. Maffia; E-mail address: lamaffia@ufv.br

* The $\boldsymbol{e}$-Xtra logo stands for "electronic extra" and indicates that the online version contains a table showing detailed information of the vegetative compatibility groups of isolates analyzed and a color version of Figure 1 showing the altitude of the sampling points.

doi:10.1094/PHYTO-98-11-1205

(C) 2008 The American Phytopathological Society disease management (30), and the use of denser plantings, may be modifying factors of the relationships in the host-environmentpathogen triangle. Epidemiologically, it is expected that as host and environment change, so too does pathogen population. Considering the present disease status, two questions arise: What is the amount and distribution of genetic variability in $C$. coffeicola populations associated with coffee plantings in MG? Do the new crop systems and/or edaphoclimatic conditions affect pathogen variability?

The investigation of the genetic structure of the pathogen population is the starting point to answer both questions. Thus, it is necessary to quantify the amount and the distribution of genetic variation to make inferences regarding population subdivision (19) and to determine whether a specific crop system favors a given genotype (37). Ultimately, this knowledge would benefit disease control, particularly breeding for resistance that can be improved, considering that new coffee cultivars can be challenged by isolates more representative of the pathogen population.

The genetic structure of a pathogen population can be assessed by morphological, molecular, selective, or neutral markers (3). Regarding the $C$. coffeicola-Coffea spp. pathosystem, it is not known whether crop systems and/or regions are strong selection factors that shape the structure of the pathogen population. Therefore, a selectively neutral marker, which does not affect fitness components, should be used to better reflect variation in the population (21).

Vegetative compatibility can be considered a neutral marker that provides information for the analysis of genetic diversity of the fungal population (21). The lack of direct effect on traits such as virulence and aggressiveness (28) is a desirable feature of the vegetative compatibility group (VCG) and the assumption that individuals of the same VCG are more genetically similar can be considered reasonable $(14,36)$. It has been observed that after identifying compatible individuals, morphological variations that were a priori observed were correlated with a given VCG $(1,19$, 
31). Nitrate-nonutilizing (nit) mutants, which do not use nitrate as nitrogen source, have been used to study VCG in many plantpathogenic fungi $(2,9,20)$. The use of nit mutants to assess vegetative compatibility was first developed for Aspergillus nidulans (11) and then adapted for Fusarium oxysporum (29) and other plant-pathogenic fungi, including $C$. kikuchii (6) and C. beticola (27). No report of using nit mutants or other techniques to assess VCGs in C. coffeicola populations is available.

Although the importance of Cercospora leaf spot in Brazil has increased, there is little information about the genetic variation in populations of $C$. coffeicola (22). Therefore, this research was conducted to determine the population structure of $C$. coffeicola associated with coffee plantings in MG state, taking into account the influence of region and crop system (organic and conventional). We hypothesized that the genetic structure of $C$. coffeicola population is affected by the geographic region and coffee crop system.

\section{MATERIAL AND METHODS}

Sampling, isolation, and selection of isolates. A hierarchical sampling scheme was set up with two levels: (i) state geographic regions (Mata, Sul, and Triângulo)-populations; and (ii) crop systems (organic and conventional)-subpopulations. In each region, diseased leaves were sampled from six plantings, three under organic and three under conventional crop systems, totaling 18 plantings in the state (Fig. 1). In each planting, a W-pattern of systematic sampling was followed in a 1-ha area, and 24 plants were randomly chosen. About 20 diseased leaves were collected from the lower, middle, and upper thirds of each plant. Sampling took place from October 2004 to February 2005. In each planting, the sampling point was geo-referenced using a portable global positioning system apparatus.

In the laboratory, isolation of $C$. coffeicola was accomplished by directly transferring pathogen structures from the leaves onto potato dextrose agar (PDA) medium; these isolates were considered as wild type. Monosporic cultures were obtained for each wild-type isolate. The monosporic isolates were characterized according to the morphology of colonies, conidia, and conidiophores $(8,12)$, and were preserved by both dehydrated mycelial disks in flasks with silica gel, kept in the dark at lab conditions, and in culture tubes with PDA.

For the experiments, five monosporic isolates, from different plants, were randomly selected from each planting. This number

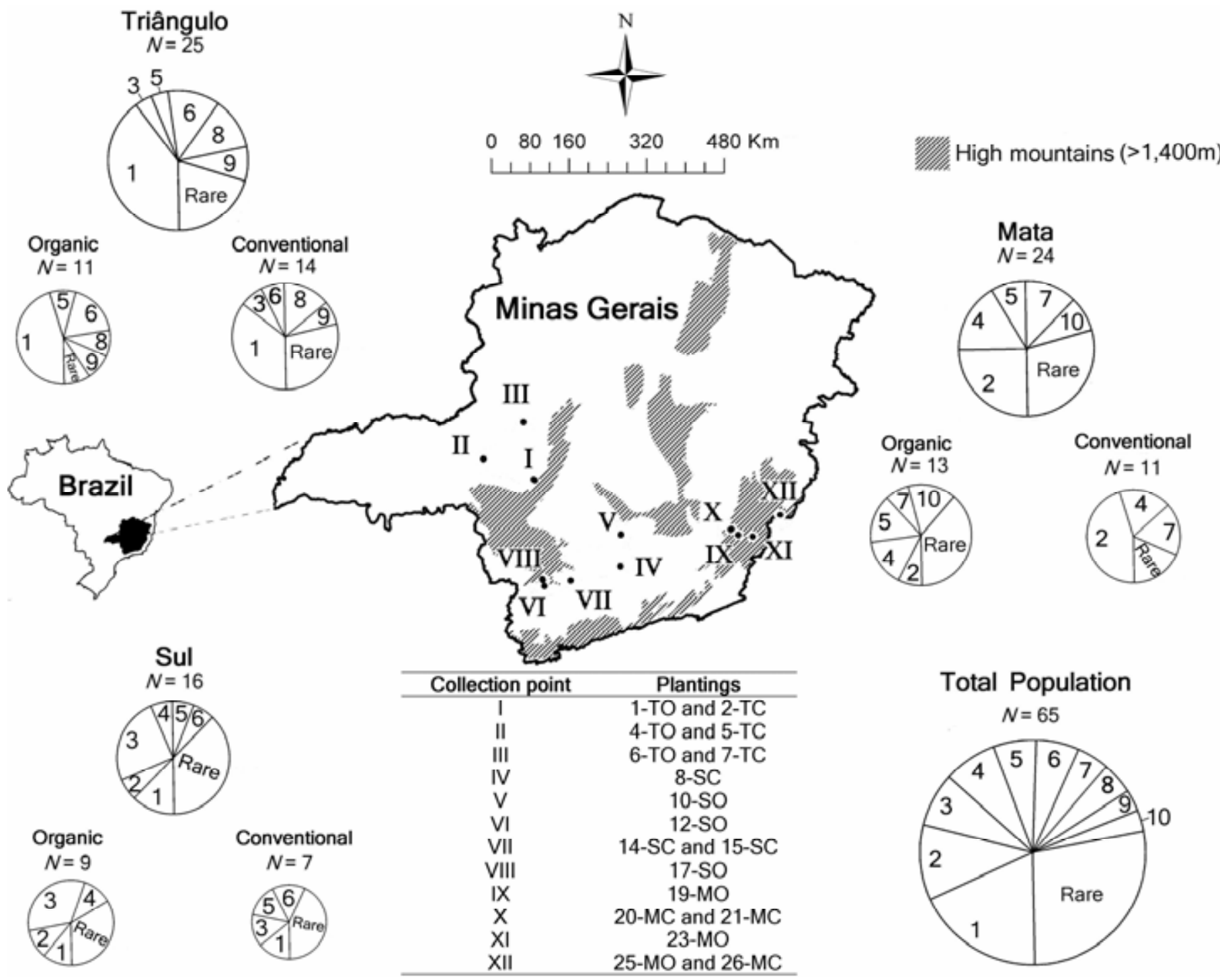

Fig. 1. Collection points (Roman numerals) in the Minas Gerais state, Brazil, of Cercospora coffeicola isolates included in 28 vegetative compatibility groups (VCGs). In each collection point, the letters after a planting number indicate the state region ( $\mathrm{T}=$ Triângulo, $\mathrm{S}=\mathrm{Sul}$, or $\mathrm{M}=\mathrm{Mata}$ ) and the coffee crop system $(\mathrm{O}=$ organic or $\mathrm{C}=$ conventional). The pie plots represent the distribution of the VCGs in each region, crop system/region, and in the total state population. The size of each plot is proportional to the number $(N)$ of individuals analyzed at the different sampled levels. The slices of the plots are proportional to the number of isolates of a given VCG (Arabic numeral inside or aside each slice). The rare VCGs/region are: 11 to 15/Triângulo; 16 to 21/Sul; and 22 to 28/Mata. 
was chosen considering the workload and operational limitations of laboratory work. A total of 90 isolates were retained for VCG typing.

Five culture media were used in different stages to determine VCGs: (i) modified Czapek dox agar: $1 \mathrm{~g}$ of $\mathrm{K}_{2} \mathrm{HPO}_{4}, 0.5 \mathrm{~g}$ of $\mathrm{MgSO}_{4} \cdot 7 \mathrm{H}_{2} 0,0.5 \mathrm{~g}$ of $\mathrm{KCl}, 0.01 \mathrm{~g}$ of $\mathrm{FeSO}_{4}, 30 \mathrm{~g}$ of sucrose, $20 \mathrm{~g}$ of agar, 1 liter of water (MCDA); (ii) nitrate Czapek dox agar: MCDA plus $2 \mathrm{~g}$ of $\mathrm{NaNO}_{3}$ (NCDA); (iii) chlorate Czapek dox agar: MCDA plus $2 \mathrm{~g}$ of $\mathrm{NaNO}_{3}$ and $30 \mathrm{~g}$ of $\mathrm{KClO}_{3}$ (CCDA); (iv) hypoxanthine Czapek dox agar: MCDA plus $0.2 \mathrm{~g}$ of hypoxanthine (HCDA); and (v) ammonium tartrate Czapek dox agar: MCDA plus $1 \mathrm{~g}$ of ammonium tartrate (TCDA).

Selection, characterization, and preservation of nit mutants. To obtain and characterize the nit mutants, we adapted the procedure developed by Cove (11) and modified by Puhalla (29). A 4-mm-diameter disk from a colony grown in NCDA was centrally planted in CCDA in a 90-mm-diameter petri dish (five dishes per isolate) and incubated in the dark at $25^{\circ} \mathrm{C}$ (these incubation conditions were followed in the remaining procedures). The colonies were inspected weekly for 6 weeks to detect chlorate-resistant sectors that grew faster than the remaining parts of the colony. Portions of these sectors were transferred to NCDA in plates and incubated for 7 days. The resulting colonies, with a thin growth of sparse or no aerial mycelium, were considered as nit mutants (9). To separate NitM or nit1/nit3 phenotypic classes, nit mutants were grown again on NCDA and HCDA. Mutants with thin growth in both media were considered NitM mutants, whereas mutants with a thin growth in NCDA but with wild-type growth on HCDA were considered nit1/nit3 mutants (9). Mutants were preserved in culture tubes with TCDA, at $5^{\circ} \mathrm{C}$ in the dark. One nit1/nit3 mutant and one NitM mutant (when possible) were selected for each original isolate, totaling 143 mutants (83 nit1/nit3 and $60 \mathrm{NitM})$.

Identification of compatibility among isolates. The preserved colonies of mutants were grown on NCDA, at $25^{\circ} \mathrm{C}$ in the dark for 7 days. Mycelial disks from nit1/nit3 and NitM mutants were taken and paired in NCDA in petri dishes to determine the vegetative compatibility. To allow for all possible pairwise combinations, the isolates were arranged 6 to $7 \mathrm{~mm}$ apart from each other in a plate. Disks (4-mm-diameter) from colonies grown on NCDA for 7 days were distributed in a petri dish so that each NitM mutant was adjacent to each nit1/nit3 mutant (Fig. 2A). Each pairing was replicated at least twice. When the results were inconsistent, the pairing was replicated two additional times. Approximately 10,650 pairings were done in total. Vegetative compatibility was checked visually at 3-day intervals, for 3 weeks.
Two paired mutants were considered as compatible, and, therefore pertaining to the same VCG, when prototrophic growth developed in the region where both colonies contacted (Fig. 2B and C).

Data analysis. Genetic variability was estimated by analyzing the frequency of VCGs at the different hierarchical levels, and the Shannon $H^{\prime}$ index of diversity was calculated. To determine how the genotypes were distributed in a sample, we calculated the evenness index $\mathrm{E}_{1}$, dividing $H^{\prime}$ by $\ln \left[E\left(g_{\mathrm{n}}\right)\right]$, where $E\left(g_{\mathrm{n}}\right)$ is the expected number of VCGs (richness), for a given sample size $(n)$. The $E\left(g_{\mathrm{n}}\right)$ was estimated using the rarefaction method (16). To contrast richness between different levels of crop system or geographic region, the expected number of VCGs was estimated for samples of sizes $\mathrm{N}=7\left(\mathrm{E}_{\mathrm{g} 7}\right)$ and $\mathrm{N}=16\left(\mathrm{E}_{\mathrm{g} 16}\right)$, the smallest sample sizes of the populations at the crop system and region levels, respectively. Differences in the $H^{\prime}$ among populations were tested based on a $90 \%$ confidence interval constructed after bootstrapping conducted with 1,000 resamples (16). Analyses were conducted in three steps: (i) all isolates, independent of the crop system and region-the total population; (ii) all isolates from a single region, independent of crop system, were considered as a population; and (iii) all isolates from a single region of a given crop system (organic or conventional), were considered as a subpopulation.

The analyses were conducted with SAS (version 9.1; SAS Institute; Cary, NC). The rarefaction estimates were obtained after compiling the algorithm $<$ Rarefac.c $>$ (16).

\section{RESULTS}

Selection and characterization of nit mutants. The level of chlorate sensitivity varied among isolates. Most isolates were chlorate sensitive, which was characterized by morphological changes in colonies grown in CCDA and normal growth in NCDA. The most sensitive isolate had a sinuous colony border (Fig. 3A and B). Identification of resistant sectors was complicated because of inherent irregularities along the edge of the colony (Fig. 3A and B). After several attempts, putative mutant sectors were obtained from areas as far as possible from the point of the initial inoculum (Fig. 3A and C).

Highest frequency of nit mutants' recovery was for colonies growing for 20 to 30 days in CCDA. Frequency of recovery varied among isolates and apparently was directly proportional to chlorate sensitivity. A low number or even no mutants were recovered when growth in CCDA approached a radial pattern (Fig. 3D). For seven chlorate insensitive isolates, no mutant sector was recovered. For 60 isolates, mutants of both nit1/ni3
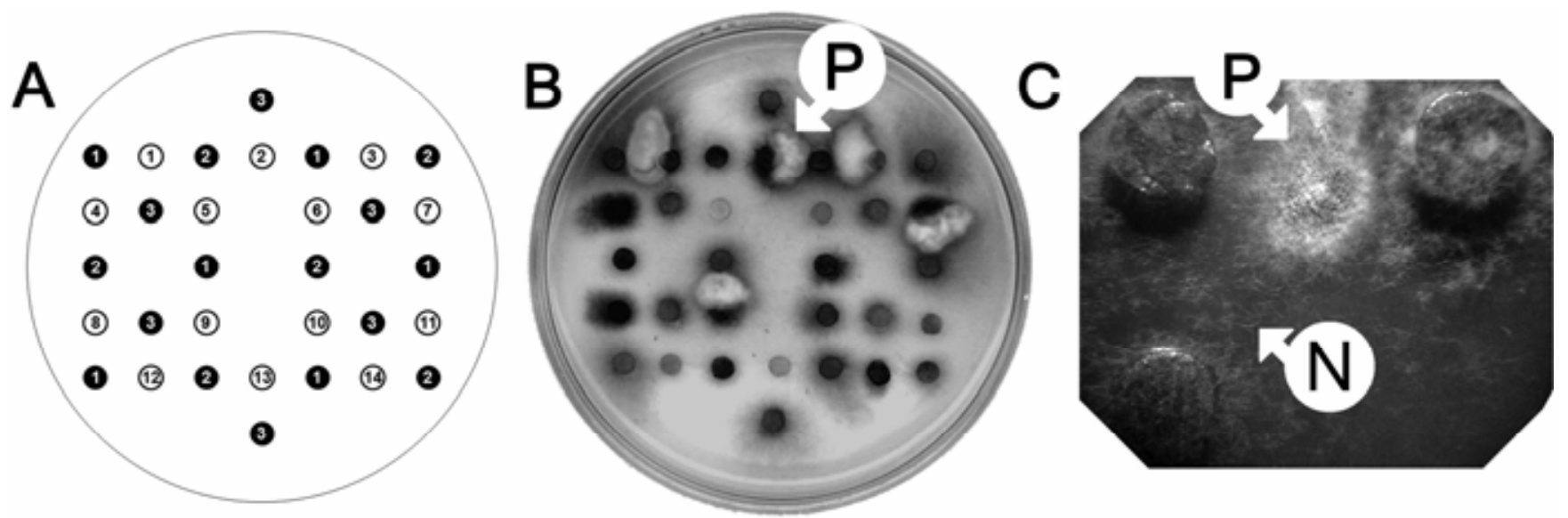

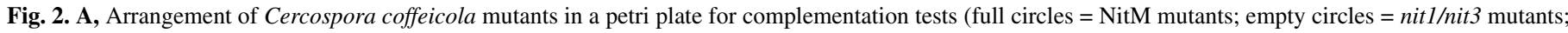

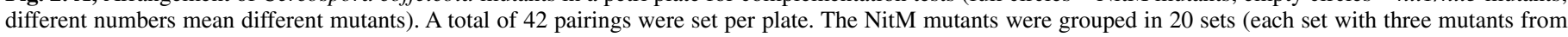

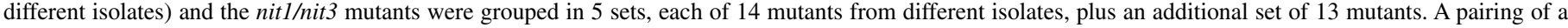

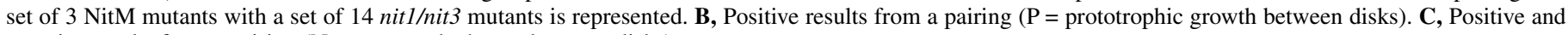
negative results from a pairing $(\mathrm{N}=$ no growth change between disks). 
and NitM phenotypes were recovered. For 23 isolates, only nit1/nit3 mutants were recovered. Therefore, the $60 \mathrm{NitM}$ mutants were paired with the 83 nitl/nit3 mutants (60 isolates for which mutants of both phenotypes were recovered +23 nitl/nit 3 only mutants).

Identification of compatibility among isolates and definition of VCGs. Both compatible and incompatible reactions were clearly distinguishable with the arrangement of mutants in the petri plates (Fig. 2B and C). Compatible reactions, observed between the 7 th and 12 th day after pairing, were characterized by a prototrophic mycelium in the contact zone of the confronted mutants, development of abundant aerial mycelium, and the expansion of prototrophic growth alongside the contact zone (Fig. $2 \mathrm{~B}$ and $\mathrm{C}$ ). In the incompatible reactions, no morphological change was observed in the contact zone (Fig. 2C). Eventually, we observed weak complementation reactions, characterized by a thin prototrophic mycelium that remained restricted to the points observed initially.

Sixty isolates paired reciprocally, whereas 15 isolates were selfincompatible. However 7 of these 15 isolates were compatible with other isolates. A total of 13 of the 23 isolates for which only nit1/nit3 mutants were obtained, were compatible with NitM mutants. Therefore, we ended up determining the VCGs for 65
$(60-15+7+13)$ isolates. Based on compatible reaction, 28 VCGs were found.

Genetic structure based on VCG analysis. Considering the total population $(\mathrm{N}=65), 10$ multimember VCGs (VCG-01, VCG-02, VCG-03, VCG-04, VCG-05, VCG-06, VCG-07, VCG08, VCG-09, and VCG-10, constituted by 12, 7, 5, 5, 4, 4, 3, 3, 2, and 2 isolates, respectively) included $72.31 \%$ of the isolates. The remaining groups, VCG-11 to VCG-28, included $27.69 \%$ of the isolates, and each group was comprised of a single isolate, which was self-compatible but incompatible with any other isolate. These VCGs were referred to as rare VCGs (Fig. 1).

Distribution and frequency of VCGs differed among regions. Considering the 28 groups detected, isolates of 11,12 , and 12 VCGs were found in the Triângulo, Sul, and Mata, respectively (Table 1). Many groups, especially rare VCGs, were restricted to specific regions. For multimember VCGs, only isolates of VCG05 were detected in all three regions; VCG-01 and VCG-03 were detected in the Sul and Triângulo; and VCG-02 and VCG-04 in the Sul and Mata regions. The Sul region included isolates of the six largest VCGs (VCG-1 to VCG-6). The remaining multimember VCGs were found in Mata (VCG-7 and VCG-10) and Triângulo (VCG-08 and VCG-09). The rare VCGs were distributed in the three regions: VCG-11 to VCG-15 in Triângulo;

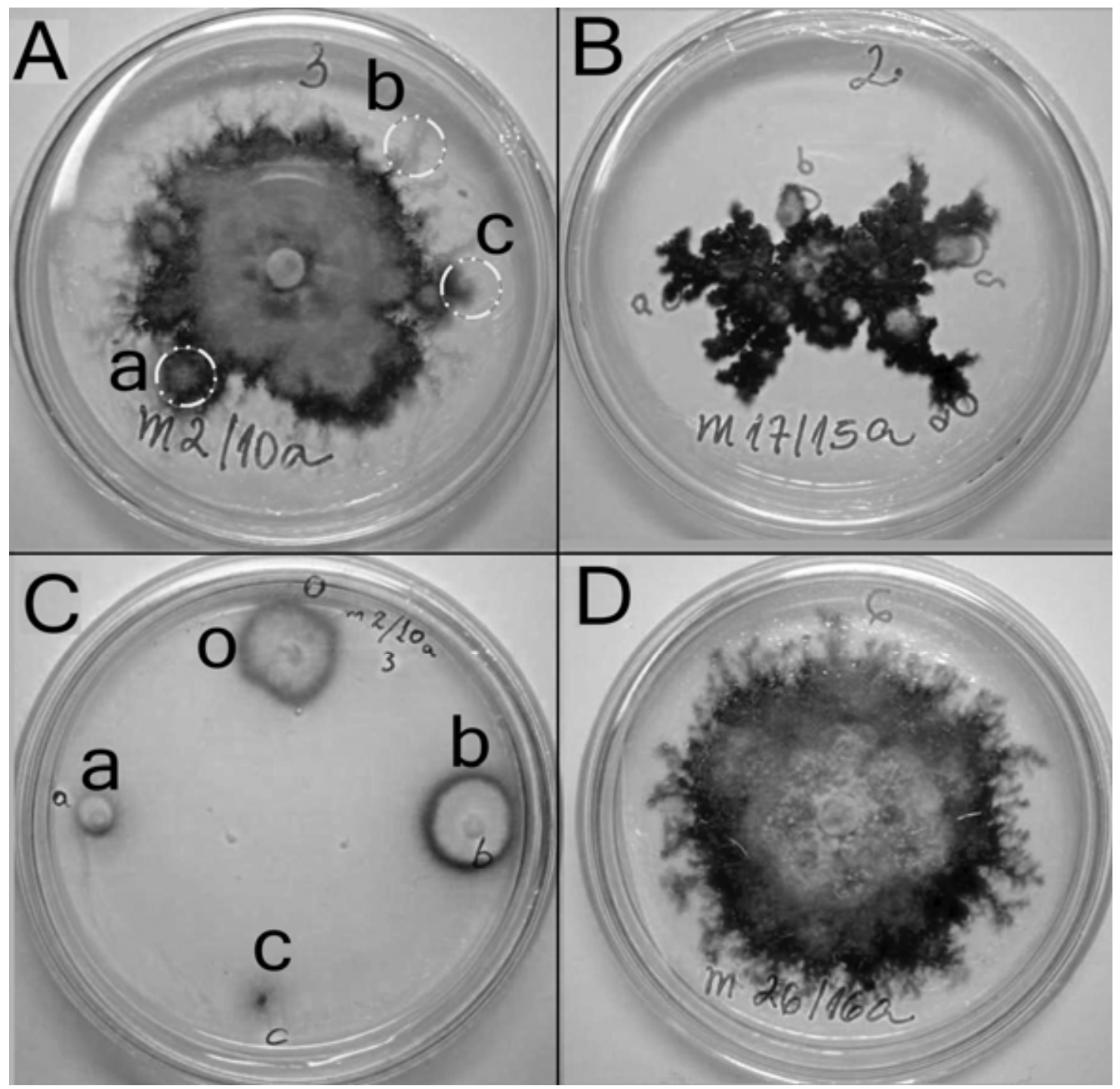

Fig. 3. A, Cercospora coffeicola colony grown in Czapek dox agar amended with $3 \% \mathrm{KClO}_{3}(\mathrm{CCDA})$. Circled areas (a, b, and c) are presumably chlorate resistant sectors that were transferred to nitrate Czapek dox agar (NCDA). B, C. coffeicola colony grown in CCDA with sensitivity to chlorate. C, Colonies in NCDA resulting from the transference in "A". Sectors a and b originated colonies with wild-type characteristics (colony 0 in the upper end) and sector $\mathrm{c}$ resulted in a Nit mutant colony with auxotrophic growth. D, Colony of $C$. coffeicola with low sensitivity to chlorate, grown in CCDA. 
VCG-16 to VCG-21 in Sul; and VCG-22 and VCG-28 in Mata. Regarding crop system, multimember VCGs (VCG-01 to VCG09) commonly occurred in both organic and conventional plantings (Fig. 1).

The values of $H^{\prime}$ were: 2.737 for Sul, 2.505 for Mata, and 2.208 for Triângulo regions. The $H^{\prime}$ in the Triângulo was 19.3 and $11.9 \%$ lower than the $H^{\prime}$ estimated for the Sul and Mata regions, respectively (Table 1). However, the estimated confidence intervals for $H^{\prime}$ for all three regions overlapped, suggesting the lack of significant differences between them (Table 1). Components for both richness, $E\left(\mathrm{~g}_{16}\right)=8.3$, and evenness, $E_{1}=0.93$, were lowest in the Triângulo (Table 1). Lowest variability estimated for Triângulo was mainly due to the richness component (27.3 and $12.5 \%$ lower than $E\left(\mathrm{~g}_{16}\right)$ calculated for Sul and Mata, respectively) rather than to evenness (17.3 and $8.6 \%$ lower than the $E_{1}$ calculated for the Sul and Mata, respectively) (Table 1).

Variability estimates also differed among regions regarding crop systems. For the Mata region, highest variability was estimated for the subpopulations from the organic system, $H^{\prime}=2.644$ (Table 1). For subpopulations from Triângulo and Sul, highest population variability was associated with conventional systems (Table 1). Considering richness, the greatest difference between crop systems was found in the Mata region; the $E\left(g_{7}\right)=6.53$ was $35.5 \%$ higher than the value estimated for the conventional subpopulation (Table 1). In the Sul, the difference in estimates of $E\left(g_{7}\right)$ for organic and conventional systems was $6.98 \%$ (Table 1 ). For evenness, the greatest difference between crop systems was found in Mata, $11.8 \%$, where the $E_{1}$ values for organic and conventional systems were 1.175 and 1.036 , respectively (Table 1). For Sul and Triângulo, the differences between crop systems were 1.1 and $2.6 \%$, respectively (Table 1 ).

\section{DISCUSSION}

This is the first report on vegetative compatibility among $C$. coffeicola isolates. We demonstrated that the technique developed by Cove (11) and modified by Puhalla (29) can be used to study vegetative compatibility reactions in $C$. coffeicola isolates. More importantly, using this technique, it was possible to detect high genetic variability in the population of $C$. coffeicola in coffee plantings.

Mutants were successfully recovered for 83 out of 90 isolates tested. The success in identifying chlorate resistant sectors in a colony was variable. For sensitive isolates, in which growth was strongly inhibited, identifying resistant sectors was not difficult as they were fast-growing sectors in a V-shape. However, for isolates that were moderately inhibited, identifying resistant sectors was difficult and subjective. Because of the sinuosity of the colony borders, finding the V- shaped sectors was confusing. Similar problems were encountered with $C$. kikuchii (6). Thus, we decided to choose the farthest points from the colony center as presumptive mutant sectors. With this procedure, the success in recovering mutants increased considerably. However, for seven isolates no mutants were recovered. Probably, the $\mathrm{KClO}_{3}$ concentration we used affected the recovery of mutants. As reported for other fungi, especially for apparently chlorate insensitive isolates, $\mathrm{KClO}_{3}$ concentration directly affects the formation of mutant sectors $(17,32)$. Increasing the concentration of $\mathrm{KClO}_{3}$ in the CCDA may increase the recovery of mutants.

The genetic basis of nitrogen absorption by $C$. coffeicola is not known. The two phenotypic classes we identified correspond to mutations in several loci in A. nidulans and Fusarium moniliforme $(9-11,34)$. However, there is no evidence regarding the number of mutated loci that govern both phenotypes in $C$. coffeicola. Therefore, we followed the terminology proposed by Correll et al. (9), and widely accepted in the research with nit mutants $(6,19,33)$. Considering the types of mutants identified, the greatest success in complementation tests is in pairings between nit1 or nit 3 with NitM mutants $(6,9,33,34)$, so we searched for these mutants. With the culture media used, we could distinguish NitM from both nit1 and nit3 mutants. As we did not attempt to separate nitl from nit3 mutants, the terminology nit1/nit3 mutant was used; separating both was irrelevant to our objectives, as mutants of either class are capable of pairing with NitM mutants $(6,9,34)$. The proportion NitM:nit1/nit3 mutant sectors in C. coffeicola was about 1:5 (data not shown), similar to the proportion of mutants reported in studies conducted with other fungi $(6,32)$.

Self-incompatibility among fungal isolates is commonly reported with nit mutants $(2,9)$, and this reaction was detected in 15 C. coffeicola isolates. However, before drawing conclusions about self-incompatibility reactions, one needs to rule out the possibility of an artifact of the technique. Fungal vegetative compatibility is determined by multiple loci (loci vic or het) $(10,25,26)$. Two fungal isolates are compatible only if they share the same alleles at all incompatibility loci. Thus, if just one allele differs between two isolates, they will be incompatible and consequently no heterokaryon will be formed $(15,21)$. No mutagenic agent is used to generate nit mutants, but the process induces a stress condition that may trigger several mutation events, includ-

TABLE 1. Estimates of the Shannon diversity index, richness, and evenness of Cercospora coffeicola populations sampled hierarchically in coffee plantings in three regions (Sul, Triângulo, and Mata) and two crop systems (organic and conventional) in the Minas Gerais state, Brazil

\begin{tabular}{lcccccc}
\hline Hierarchical level & Sample size $(n)$ & $g_{\text {obs }}{ }^{\mathrm{a}}$ & $E\left(g_{\mathrm{n}}\right)^{\mathrm{b}}$ & $E\left(g_{7}\right)^{\mathrm{c}}$ & $E\left(g_{16}\right)^{\mathrm{d}}$ & $H^{\mathrm{e}}$ \\
\hline Region/crop system & & & & & & \\
$\quad$ Mata/organic (O) & 13 & 10 & 9.48 & 6.53 & N/A & $2.644(0.362-2.926)^{\mathrm{g}}$ \\
Mata/conventional (C) & 11 & 5 & 4.80 & 4.21 & N/A & $1.625(1.267-1.983)$ \\
Sul/O & 9 & 7 & 6.33 & 6.45 & N/A & $2.218(1.822-2.614)$ \\
Sul/C & 7 & 7 & 6.00 & 6.00 & N/A & $2.274(1.900-2.649)$ \\
Triângulo/C & 14 & 9 & 8.53 & 5.46 & N/A & $2.293(1.931-2.656)$ \\
Triângulo/O & 11 & 6 & 5.63 & 4.67 & N/A & $1.802(1.407-2.198)$ \\
Region & 16 & 12 & 11.41 & 6.11 & 11.41 & $2.737(2.434-3.039)$ \\
Sul & 24 & 12 & 11.72 & 5.30 & 9.48 & $2.505(2.245-2.765)$ \\
Mata & 25 & 11 & 10.73 & 4.64 & 8.30 & $2.208(1.881-2.535)$ \\
Triângulo & 65 & 28 & 27.72 & 5.87 & 11.14 & $3.180(2.980-3.780)$ \\
Total population & & & & & 1.070 \\
\hline
\end{tabular}

${ }^{a}$ Number of vegetative compatibility groups (VCGs) observed.

${ }^{\mathrm{b}}$ Expected number of VCGs calculated for the correspondent sample size ( $n$ ) estimated by the rarefaction method (16).

c Expected number of VCGs calculated for a sample of size $n=7$ per subpopulation estimated by the rarefaction method.

${ }^{\mathrm{d}}$ Expected number of VCGs calculated for a sample of size $n=16$ per population estimated by the rarefaction method. This index was calculated only for subpopulations with large enough sample sizes. N/A = not applicable.

e VCG diversity based on the Shannon index.

${ }^{\mathrm{f}}$ Evenness calculated by scaling the Shannon index by the expected number of VCGs $\left\{\ln \left[\mathrm{E}\left(g_{\mathrm{n}}\right)\right]\right\}$ to adjust for sample size dependence (16).

g Numbers in parentheses indicate $90 \%$ confidence interval calculated by bootstrapping (1,000 resamples) using the BCa method (16). 
ing the activity of transposable elements in the fungal genome (13). With the experimental procedures employed, only mutants with phenotypes related to nitrogen absorption are identified (9), and there is no control on mutation in other loci, such as those involved in vegetative incompatibility. A selected nit mutant could also carry mutation in a locus of vegetative incompatibility. If this happened, a false incompatibility reaction would be observed. Following this reasoning, positive reactions are reliable, as there is low probability that the same mutation occurs in two incompatible isolates resulting in the formation of the same alleles in the same incompatibility loci. It is highly likely that one of the nitl/nit3 and NitM mutants obtained for the self-incompatible isolates had mutations in the loci that govern vegetative incompatibility. Indirect evidence came from compatibility reaction in the pairing of the self-incompatible mutants (NitM or nit1/nit3) with mutants of other isolates.

Related to the weak compatibility reactions, it is hypothesized that eventually the process of cell death in the incompatible reaction may have been triggered slowly, allowing for the production of enzymes responsible for nitrogen absorption in the contact point before the heterokaryotic cells died $(18,24)$. Thus, the weak reactions were not considered as positive in identifying groups. These reactions have been described, and it seems there is a consensus of not considering them as positive $(7,20)$.

Little information on how to preserve nit mutants is available. Preservation is crucial, mostly when VCG is to be used as a marker in studies of genetic structure of fungal populations. These studies require a high number of isolates and commonly the mutants to be paired are not produced at the same time. The mutants were preserved for a long time in CDA amended with ammonium tartrate (TCDA). Most organisms absorb nitrogen basically as ammonium (9). As nit mutants cannot reduce other forms of nitrogen to ammonium $(9,11,34)$, we hypothesized that growing these mutants in TCDA would preserve them efficiently. Phenotype stability of nit mutants preserved in TCDA was recorded throughout this study, which lasted about 1 year. We found just one reversion from the mutant preserved to the wild type when it was cultivated in NCDA.

The isolates of $C$. coffeicola were included in 28 VCGs, and 18 groups were formed by a single isolate. Similar results regarding genetic variability were reported for other Cercospora spp. (4$6,27)$. Nevertheless, the implications of this fact for the reproduction mode and consequently for the population structure remain to be elucidated.

Region and crop system had no effect on the genetic structure of the pathogen population. When analyzing variability estimates and components, higher values were always due to differences between isolates within subpopulations (data not shown). Two reasons may explain this fact: (i) organic coffee plantings became more widespread recently, less than three decades ago (23). Therefore, the time-span may not be long enough to allow for changes in the genetic structure of the pathogen population; and (ii) C. coffeicola is mostly wind-dispersed, and coffee plantings, regardless of crop systems, are geographically close. Thus, considering both wind dispersal of conidia and proximity of plantings within regions, it is expected that the plantings in a region will share common individuals. For example, plantings 1-TO (organic) and 2-TC (conventional) sampled in the Triângulo (Fig. 1), are $1.9 \mathrm{~km}$ apart; estimates of diversity were similar for both plantings (data not shown).

It seems that the $C$. coffeicola population in MG follows a regional pattern of VCG distribution. Among the 28 VCGs we characterized, only VCG-05 was found in the three regions, although it was not prevalent in any region. The most prevalent groups in the Triângulo, Mata, and Sul regions were VCG-01, VCG-02, and VCG-03, respectively. The most prevalent VCG in the Triângulo was not detected in the Mata, and vice-versa. Both VCG-1 and VCG-2 were found in the Sul. High mountains can serve as natural barriers to migration, particularly between the Triângulo and the other two regions (Fig. 1). Thus we assume that migration between regions is limited, but individuals are exchanged between subpopulations within a region.

In conclusion, with the sampling design we followed, it was possible to evaluate the genetic structure of $C$. coffeicola in three regions. These three populations are not completely isolated, and they share isolates of the same VCGs. Regardless of geographic region, genetic variability in populations associated with organic and conventional plantings was high. There is no strong evidence to support the working hypothesis, and we can conclude that based on VCGs there is no effect of geographic region or crop system on the population of $C$. coffeicola in MG. The same collection of isolates is being studied with other markers (morphological and molecular) to characterize the variability in C. coffeicola.

\section{ACKNOWLEDGMENTS}

This study was funded by Fundação de Amparo à Pesquisa do Estado de Minas Gerais (FAPEMIG) and Conselho Nacional de Desenvolvimento Científico e Tecnológico ( $\mathrm{CNPq})$. We acknowledge $\mathrm{H}$. Teixeira (EPAMIG) and C. C. Nunes who contacted coffee growers; and N. J. Grünwald (Oregon State University, Department of Botany and Plant Pathology) who provided an SAS program and the $<$ Rarefac.c $>$ algorithm.

\section{LITERATURE CITED}

1. Botseas, D. D., and Rowe, R. C. 1994. Development of potato dying in response to infection by two pathotypes of Verticillium dahliae and coinfection by Pratylenchus penetrans. Phytopathology 84:275-282.

2. Brooker, N. L., Leslie, J. F., and Dickman, M. B. 1991. Nitrate nonutilizing mutants of Colletotrichum and their use in studies of vegetative compatibility and genetic relatedness. Phytopathology 81:672-677.

3. Burdon, J. J. 1993. The structure of pathogen populations in natural plant communities. Annu. Rev. Phytopathol. 31:305-323.

4. Cai, G., and Schneider, R. W. 2002. Use of nitrate nonutilizing mutants to examine vegetative compatibility groups in Cercospora kikuchii. (Abstr.) Phytopathology 92(suppl.):S11.

5. Cai, G., and Schneider, R. W. 2003. Vegetative compatibility grouping in Cercospora kikuchii. (Abstr.) Phytopathology 93(suppl.):S13.

6. Cai, G., and Schneider, R. W. 2005. Vegetative compatibility groups in Cercospora kikuchii, the causal agent of cercospora leaf blight and purple seed stain in soybean. Phytopathology 95:257-261.

7. Chandelier, A., Laurent, F., Dantinne, D., Mariage, L., Etienne, M., and Cavelier, M. 2003. Genetic and molecular characterization of Verticillium dahliae isolates from woody ornamentals in Belgian nurseries. Eur. J. Plant Pathol. 109:943-952.

8. Chupp, C. A. 1953. A Monograph of the Fungus Genus Cercospora. Ronald Press Co., Ithaca, NY.

9. Correll, J. C., Klittich, C. J. R., and Leslie, J. F. 1987. Nitrate nonutilizing mutants of Fusarium oxysporum and their use in vegetative compatibility tests. Phytopathology 77:1640-1646.

10. Cortesi, P., and Milgroom, M. G. 1998. Genetics of vegetative incompatibility in Cryphonectria parasitica. Appl. Environ. Microbiol. 64:2988-2994

11. Cove, D. J. 1976. Chlorate toxicity in Aspergillus nidulans. Mol. Gen. Genet. 146:147-159.

12. Crous, P. W., and Braun, U. 2003. Mycosphaerella and its anamorphs: 1. Names published in Cercospora and Passarola. Centraalbureau voor Schimmelcultures, The Netherlands.

13. Daboussi, M. J., and Capy, P. 2003. Transposable elements in filamentous fungi. Annu. Rev. Microbiol. 57:275-299.

14. Dobinson, K. F., Harrington, M. A., Omer, M., and Rowe, R. C. 2000. Molecular characterization of vegetative compatibility group $4 \mathrm{~A}$ and $4 \mathrm{~B}$ isolates of Verticillium dahliae associated with potato early dying. Plant Dis. 84:1241-1245.

15. Glass, N. L., Jacobson, D. J., and Shiu, P. K. T. 2000. The genetics of hyphal fusion and vegetative incompatibility in filamentous Ascomycete fungi. Annu. Rev. Genet. 34:165-186.

16. Grünwald, N. J., Goodwin, S. B., Milgroom, M. G., and Fry, W. E. 2003. Analysis of genotypic diversity data for populations of microorganisms. Phytopathology 93:738-746.

17. Jacobson, D. J., and Gordon, T. R. 1988. Vegetative compatibility and self-incompatibility within Fusarium oxysporum f. sp. melonis. Phytopathology 78:668-672. 
18. Joaquim, T. R., and Rowe, R. C. 1990. Reassessment of vegetative compatibility relationships among strains of Verticillium dahliae using nitrate-nonutilizing mutants. Phytopathology 80:1160-1166.

19. Korolev, N., Katan, J., and Kayan, T. 2000. Vegetative compatibility groups of Verticillium dahliae in Israel: Their distribution and association with pathogenicity. Phytopathology 90:529-536.

20. Korolev, N., and Katan, T. 1997. Improved medium for selecting nitratenonutilizing (nit) mutants of Verticillium dahliae. Phytopathology 87:1067-1070.

21. Leslie, J. F. 1993. Fungal vegetative compatibility. Annu. Rev. Phytopathol. 31:127-150.

22. Lombardi, A. P. Z., Kurozawa, C., Izioka, E. K., and Rosa, D. 2002. Caracterização morfológica, patogênica e molecular de Cercospora coffeicola. (Abstr.) Fitopatol. Bras. 27(suppl.):S217.

23. Marciano Da Costa, L., Olszevski, N., and Mônaco, P. A. L. 2003. Manejo e conservação de solos para a cultura do cafeeiro. Pages 367-396 in: Produção Integrada de Café. L. Zambolim, ed. Suprema Grafica Editora LTDA, Visconde do Rio Branco, Brazil.

24. Marek, S. M., Wu, J., Glass, N. L., and Gilchrist, D. G. 2003. Nuclear DNA degradation during heterokaryon incompatibility in Neurospora crassa. Fungal Genet. Biol. 40:126-137.

25. Marra, R. E., and Milgroom, M. G. 2000. The mating system of the fungus Cryphonectria parasitica: Selfing and self-incompatibility. Heredity 86:134-143.

26. McGuire, I. C., Davis, J. E., Double, M. L., McDonald, W. L., and Rauscher, J. T. 2005. Heterokaryon formation and parasexual recombination between vegetatively incompatible lineages in a population of chestnut blight fungus, Cryphonectria parasitica. Mol. Ecol. 14:3657-3669.

27. Moretti, M., Saracchi, M., and Farina, G. 2006. Vegetative compatibility groups in Cercospora beticola. (Abstr.) Phytopathology 96(suppl.):S140.
28. Nauta, M. J., and Hoekstra, R. F. 1996. Vegetative incompatibility in Ascomycetes: Highly polymorphic but selectively neutral? J. Theor. Biol. 183:67-76.

29. Puhalla, J. E. 1985. Classification of strains of Fusarium oxysporum on the basis of vegetative compatibility. Can. J. Bot. 63:179-183.

30. Ricci, M. S. F., Araújo, M. C. F., and Franch, C. M. C. 2002. Cultivo orgânico do café-Recomendações técnicas. EMBRAPA, Brasília-DF.

31. Strausbaugh, C. A., Schroth, M. N., Weinhold, A. R., and Hancock, J. G. 1992. Assessment of vegetative compatibility of Verticillium dahliae tester strains and isolates from California potatoes. Phytopathology 82:6168 .

32. Swift, C. E., Wickliffe, E. R., and Schwartz, H. F. 2002. Vegetative compatibility groups of Fusarium oxysporum f. sp. cepae from onion in Colorado. Plant Dis. 86:606-610.

33. Tsror (Lahkim), L., and Levin, A. G. 2006. Vegetative compatibility and pathogenicity of Verticillium dahliae Kleb. isolates of olive Israel. J. Phytopathol. 151:451-455.

34. Vannacci, G., and Cristani, C. 1998. Characterization of chlorate-resistant sectors from isolates of Fusarium moniliforme and $F$. proliferatum. J. Microbiol. Methods 31:175-184.

35. Zambolim, L., do Vale, F. X. R., Pereira, A. A., and Chaves, G. M. 1997. Café (Coffea arabica L.) - Controle de Doenças. Pages 83-180 in: Controle de Doenças de Plantas - Grandes Culturas. F. X. R. do Vale and L. Zambolim, eds. Editora UFV, Viçosa, Brazil.

36. Zeise, K., and Von Tiedmann, A. 2001. Morphological and physiological differentiation among vegetative compatibility groups of Verticillium dahliae in relation to V. longisporum. J. Phytopathol. 149:469-475.

37. Zwankhuizen, M. J., Govers, F., and Zadoks, J. C. 1998. Development of potato late blight epidemics: Disease foci, disease gradients, and infection sources. Phytopathology 88:754-763. 